\title{
Five genetic markers in the interleukin 1 family in relation to inflammatory bowel disease
}

\author{
P C F Stokkers, B E van Aken, N Basoski, P H Reitsma, G N J Tytgat, S J H van Deventer
}

\begin{abstract}
Background-An imbalance between the proinflammatory cytokine interleukin $1 \beta$ (IL-1ß) and the anti-inflammatory cytokine IL-1 receptor antagonist (IL-1ra) has been postulated as a pathogenic factor in inflammatory bowel disease (IBD). Aims-To study allelic frequencies of novel polymorphisms in the genes for IL-1 $\beta$ and IL-1ra in patients with IBD and to assess the relation between ex vivo cytokine production and allelic variants of the IL-1 $\beta$ and IL-1ra genes.
\end{abstract}

Subjects-Two hundred and seventy healthy controls, 74 patients with ulcerative colitis (UC), 72 with Crohn's disease (CD), 40 with primary sclerosing cholangitis for the allelic frequencies, and 60 healthy individuals for the ex vivo stimulation test.

Methods-Genotyping was performed by polymerase chain reaction and subsequent cleavage with specific endonucleases (Mwo1, MspAI1, Alu1, Taq1, BsoF1) for five novel restriction fragment length polymorphisms (RFLPs) in the genes for IL-1ra and IL-1B.

Results-No significant differences were found in the allelic frequencies or allele carriage rates of the markers in the IL-1ß and IL-1ra genes between CD, UC, and healthy controls. No association between the genetic markers and cytokine production levels was observed. Patients with UC carried the combination of both the infrequent allele of the Taq1 RFLP and the Mwo1 RFLP significantly more frequently (35.2\% in UC versus $71.1 \%$ in controls).

Department of Gastroenterology and Hepatology, Academic Medical Centre, Amsterdam, The Netherlands P C F Stokkers $\mathrm{B}$ E van Aken N Basoski

P H Reitsma G N J Tytgat S J H van Deventer

Correspondence to: Dr P C F Stokkers,

Laboratory for Experimental Internal Medicine,

Department of

Gastroenterology and

Hepatology, Academic

Medical Centre,

Meibergdreef 9 ,

$1105 \mathrm{AZ}$ Amsterdam,

The Netherlands.

Accepted for publication 2 December 1997

Keywords: cytokine gene polymorphisms; interleukin 1 receptor antagonist; interleukin $1 \beta$; Crohn's disease; ulcerative colitis

The genetic background of inflammatory bowel disease (IBD) has been intensively studied in recent years. In particular genes on chromosome 6 , including the HLA class 2 genes and the genes for tumour necrosis factor (TNF) $\alpha$ and $\beta$ have been studied as candidate genes. These efforts have yielded several associations between alleles of these genes and either IBD, ulcerative colitis (UC), or Crohn's disease (CD). ${ }^{12}$ Recent linkage analyses have confirmed a role for the HLA region in UC but not CD. ${ }^{34}$ However, an extended haplotype of the TNF genes on chromosome 6 has been associated with $\mathrm{CD} .^{5}$ Recently genome wide screenings have yielded susceptibility loci for IBD on chromosomes 3, 7, and 12 and for CD on chromosome $16 .^{6-8}$

The interleukin 1 (IL-1) gene cluster on chromosome 2 has received particular attention as a candidate locus for a role in the pathogenesis of IBD. IL-1 $\beta$ is a potent proinflammatory cytokine ${ }^{9}$ and IL-1 receptor antagonist (IL-1 ra) is its naturally occurring antagonist; both are expressed in the mucosa of patients with IBD. ${ }^{10-14}$ An imbalance between mucosal levels of IL-1 $\beta$ and IL-1ra in patients with IBD has been claimed to play a role in the pathogenesis of IBD. ${ }^{15}$ This imbalance may very well be under genetic control of the genes encoding these cytokines. Indeed, an association between UC and a variable number of tandem repeats (VNTR) in intron 2 of the IL-1 ra gene (IL-1RN) has been reported $^{16}$ although others did not completely confirm this finding. ${ }^{17-21}$ Additionally, the production rates of the proinflammatory cytokine IL-1 $\beta$ and anti-inflammatory cytokine IL-1 ra seem to be genetically determined and are associated with genetic markers. ${ }^{22-24}$

The genes of IL- $1 \alpha$ (IL1A), IL-1 $\beta$ (IL1B), and IL-1 ra (IL1RN) are located close to each other on chromosome 2q12-21 and their genomic sequence is known. ${ }^{25-31}$ Recently several novel restriction fragment length polymorphisms (RFLPs) in IL1B and IL1RN have been reported that are more informative than the previously recognised polymorphisms. ${ }^{32}$

Our aim was to determine the allelic frequencies for these novel polymorphisms in a panel of patients with IBD from the department of gastroenterology and in healthy controls. We also investigated the relation between the genetic markers and cytokine production in healthy volunteers by means of ex vivo whole blood stimulation assays.

\section{Materials and methods} PATIENTS

Blood samples were obtained from 273 healthy individuals recruited among the employees of our hospital, and from 75 patients with UC, 74 with CD, and 40 with primary sclerosing cholangitis (PSC). Twenty seven patients with PSC had concomitant UC, and 10 had concomitant CD. The patients with UC (41 men, 34 women) had a median age of 38.4 years, with a median age of disease onset of 28.9 years, and a median disease duration of 9.1 years. The patients with CD (19 men, 55 
Table 1 Disease extent in patients with IBD

\begin{tabular}{lcc}
\hline Disease extent & Crohn's disease (\%) & Ulcerative colitis (\%) \\
\hline Proctitis & 3 & 11 \\
Sigmoiditis & 2 & 19 \\
Left sided colitis & 7 & 23 \\
Pancolitis & 23 & 44 \\
Ileum + colon & 32 & 0 \\
Small bowel & & \\
$\quad$ disease & 30 & 0 \\
Data missing & 3 & 3 \\
\hline
\end{tabular}

women) had a median age of 38.6 years, a median age of disease onset of 27.7 years, and a median disease duration of 10.9 years. The patients with PSC (23 men, 17 women) had a median age of 45.2 years (median age of onset and disease duration are not known for this group). For all patients with IBD the family history for IBD was negative. All patients were unrelated inhabitants of the Amsterdam area. The diagnosis of IBD had been made prior to the study by conventional radiological, endoscopic, and histological criteria. Table 1 presents details of disease extent.

DNA ISOLATION

White blood cells were isolated from $10 \mathrm{ml}$ EDTA blood samples followed by sodium dodecyl sulphate (SDS)/proteinase $\mathrm{K}$ digestion. DNA extraction was performed by means of phenol/high salt extraction and ethanol precipitation. ${ }^{33}$ The DNA was resuspended in TE (Tris/EDTA) buffer ( $\mathrm{pH}$ 8) and the samples were stored at $4^{\circ} \mathrm{C}$.

POLYMORPHISM SCREENING

For all polymorphisms the polymerase reaction was used followed by digestion with specific enzymes as described previously. ${ }^{32}$ All reactions were performed blinded with respect to patient status.

\section{IL-1 $\beta$ gene}

Two novel polymorphisms were studied in addition to the previously reported Taq 1 polymorphism in the IL-1 $\beta$ gene (IL1B) - that is, a BsoF1 RFLP in intron 4 and an Alu1 RFLP in the promoter region of the gene. ${ }^{32}$

\section{IL-1ra gene}

We recently reported four novel polymorphisms in the IL-1ra gene (IL1RN) ${ }^{32}$ : an MspI RFLP in exon 2, an Mwo1 RFLP in intron 2, an SspI RFLP in intron 3, and an MspA1I RFLP in exon 4 . The first three polymorphisms and the VNTR in intron 2 are in tight linkage disequilibrium (fig 1). ${ }^{34}$ We therefore selected the MspA1I and MwoI polymorphisms for further study.

WHOLE BLOOD STIMULATION

To limit circadian variation in cytokine production, blood from the 60 healthy participants was obtained between 0900 and $10 \quad 00$ am. ${ }^{35}{ }^{36}$ Blood was collected into pyrogen free tubes (Sarstedt, Nümbrecht, Germany), containing pyrogen free heparin (Thromboliquine, Organon, Oss, The Netherlands; final concentration $30 \mathrm{IU} / \mathrm{ml}$ ). Heparinised blood aliquots $(1 \mathrm{ml}$ ) were diluted $1 / 1$ in Hank's buffered saline solution (Biowhittaker, Heidelberg, Germany) in pyrogen free tubes (Falcon, Becton Dickinson, Mountain View, California, USA) and incubated with Escherichia coli 0111:B4 lipopolysaccharide (LPS) (Difco Laboratories, Detroit, Michigan, USA) at a final concentration of $10 \mathrm{ng} / \mathrm{ml}$. After 24 hours incubation at $37^{\circ} \mathrm{C}$ in a $\mathrm{CO}_{2}$ incubator, plasma was prepared by centrifugation at $800 \mathrm{~g}$ for 10 minutes at $4^{\circ} \mathrm{C}$. Samples were diluted in enzyme linked immunosorbent assay (ELISA) dilution buffer (CLB, Amsterdam, The Netherlands), and analysed in parallel for IL-1 $\beta$ and IL-1ra. A time response curve showed that after 8 to 12 hours' stimulation with LPS the IL-1 $\beta$ and IL-1 ra response reaches a plateau which remains unchanged for 24 hours, in accordance with findings previously reported. ${ }^{37}$

IL-1 $\beta$ was determined by ELISA using mouse antihuman IL-1 $\beta$ (58.121.08, Biosource, Brussels, Belgium) as capture antibody. The standard curve was prepared from recombinant human IL-1 $\beta$ (58.121.10, Biosource); biotinylated mouse antihuman IL-1 $\beta$ (58.121.03, Biosource) was used as the detection antibody and was conjugated with HRPstreptavidin (CLB).

IL-1 ra was assayed by ELISA using mouse antihuman IL-1 ra (Antibody Solutions, SARL Illkirch, France). The standard curve was prepared from recombinant human IL-1RA (280RA-101, R\&D Systems Europe, Abington, UK); biotinylated goat antihuman IL-1 ra (BAF280, R\&D) was used as the detection antibody.

For leucocyte counts, blood was drawn into $\operatorname{EDTA}\left(\mathrm{K}_{3}\right)$ tubes, and numbers were assessed routinely with the use of a flow cytometer (Technicon H1 system, Technicon Instruments, Tarrytown, USA).

\section{STATISTICS}

The results are presented as genotypes and allele frequencies for each polymorphism. $\chi^{2}$ Tests for statistical significance were performed on genotype frequencies. The significance was assessed with the CLUMP computer program, which uses a Monte Carlo approach. ${ }^{38}$ The CLUMP program performs repeated simulations to generate tables having the same totals as the tested results, and counts the number of times that the found $\chi^{2}$ value is achieved by the randomly simulated data. This method has the advantage that a Bonferroni correction is not necessary. Carriers of both infrequent alleles of the two RFLPs were defined as those patients that were heterozygous for at least both infrequent alleles. Risk estimates were made on $2 \times 2$ contingency tables and $95 \%$ confidence intervals (CI) were calculated for the different disease classifications in carriers of specific alleles. ${ }^{39}$

Statistical analysis of the cytokine production in relation to the different genotypes was done by linear regression and one way analysis of variance, assuming a normal distribution, after performing a Shapiro and Wilk W test and removing outlying values. A $t$ test was used for the comparison of cytokine production between two genotypes. Probability values from 


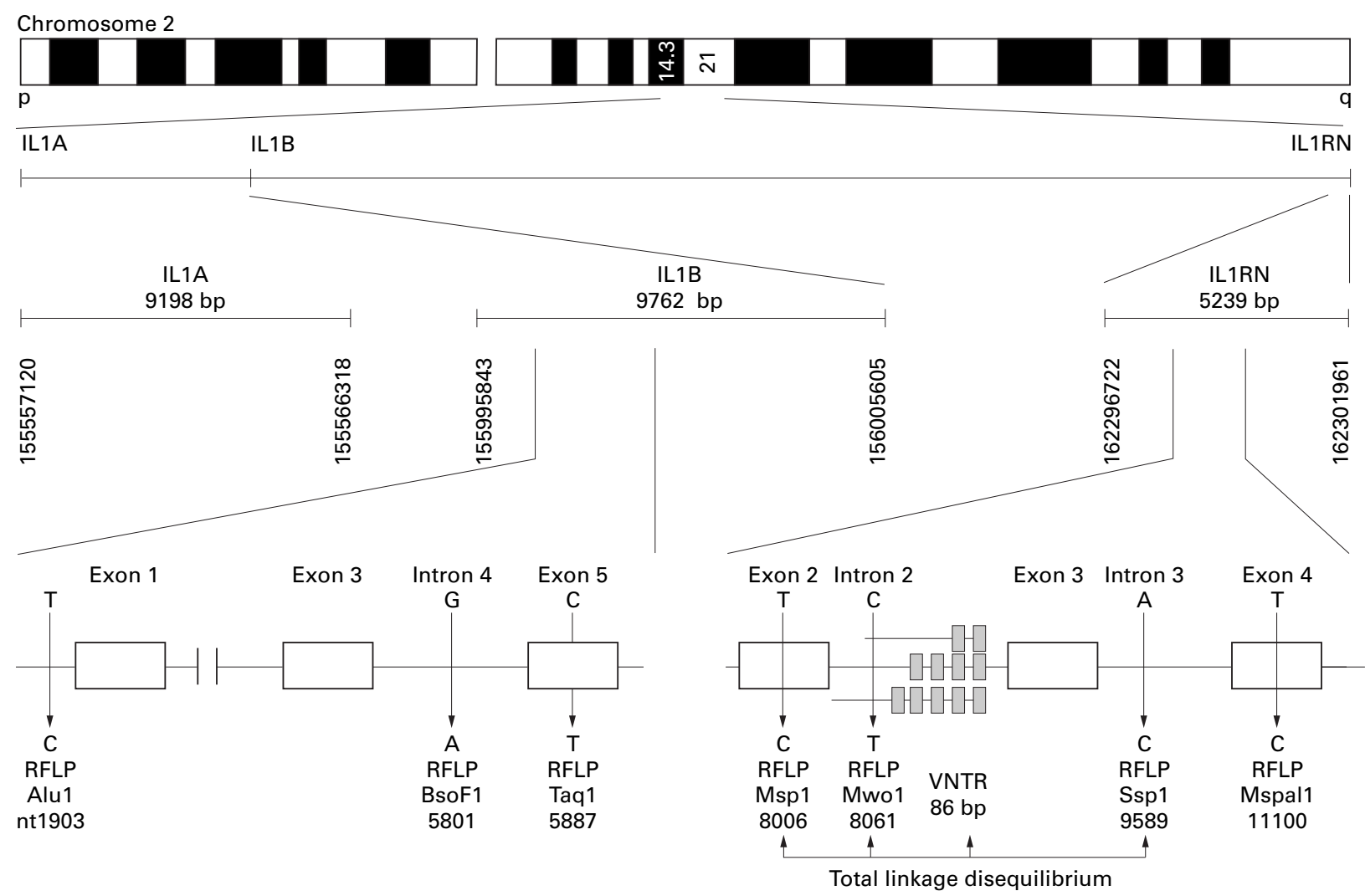

Figure 1 RFLPs in IL1RN. IL1A and IL1B are located close together on band q14.3 on chromosome 2 (first panel). IL1RN is located on q21 at a distance of about $7 \mathrm{cM}$ from the IL1A/B locus (second panel). The third panel indicates the size of the IL1A, B, and IL1RN loci. The numbers indicate the nucleotide number of the NCBI-chromosome 2 map. The lower panel depicts the position of the RFLPs studied. The RFLPs joined by the arrows are in tight linkage disequilibrium.

this test were corrected for multiple comparisons by multiplying the $\mathrm{p}$ value by the number of comparisons that were made (Bonferroni correction). Calculation of confidence intervals for the cytokine production assays was done by grouping the tested persons in allele 1 homozygotes and allele 2 carriers and subsequent calculation of the mean difference and standard error of the mean difference. Unless otherwise indicated data are presented as mean (SEM).

\section{Results}

ALLELE FREQUENCIES OF THE RFLPS IN RELATION TO UC, CD, AND PSC

Tables 2 and 3 respectively present the allele frequencies of the Taq1 polymorphism in IL-1B and the Mwo1 polymorphism in IL$1 \mathrm{RN}$ (data on other RFLPs not shown). We were particularly interested in carriage rates of both the infrequent allele of the Mwo1 RFLP and the infrequent allele of the Taq I RFLP, as these RFLPs are reported to be linked with cytokine prduction. Carriage of both infrequent alleles seemed to be associated with UC, yielding a relative risk of 2.6 (95\% CI 1.33 to 5.18) (fig 2). All combinations between the other markers in IL1B and IL-1RN were tested, but no associations with the disease groups were found (data not shown).

GENETIC MARKERS IN RELATION TO CYTOKINE PRODUCTION

No relation was found between IL- $1 \beta$ production and the genotypes of the BsoF1 RFLP (1/1: $1.6(0.2), 1 / 2: 1.2(0.1), 2 / 2: 2.6(0.6)$ $\mathrm{ng} / 10^{6}$ cells, $\mathrm{p}=0.33$; see fig $3 \mathrm{~B}$ ) or for the genotypes of the Alu1 RFLP (1/1: $1.6(0.2)$, 1/2: $1.4(0.2), 2 / 2: 1.6(0.4) \mathrm{ng} / 10^{6}$ cells, $\mathrm{p}=0.69$; see fig $3 \mathrm{C}$ ) following ex vivo stimulation of whole blood with LPS. There was also no relation between IL-1ra levels and the genotypes of the MspA1 RFLP (1/1: 6.3 (0.5), 1/2: 6.3 (0.6), 2/2: 9.1 (1.7) $\mathrm{ng} / 10^{6}$ cells,

Table 2 Taq1 restriction fragment length polymorphism in the interleukin-1 $\beta$ gene: genotype frequencies, allele frequencies and carriage rates in IBD

\begin{tabular}{|c|c|c|c|c|c|c|c|c|}
\hline \multirow[b]{2}{*}{ Taq1 } & \multicolumn{4}{|c|}{ Genotype frequency } & \multicolumn{2}{|c|}{ Allele frequency } & \multicolumn{2}{|c|}{ Carriage rate } \\
\hline & $1 / 1$ & $1 / 2$ & $2 / 2$ & $p^{*}$ & 1 & 2 & 1 & 2 \\
\hline Healthy $(n=256)$ & 57.8 & 35.9 & 6.3 & & 75.8 & 24.2 & 93.8 & 42.2 \\
\hline $\mathrm{CD}(\mathrm{n}=65)$ & 72.3 & 23.1 & 4.6 & 0.09 & 83.8 & 16.2 & 95.4 & 27.7 \\
\hline CD+PSC $(n=74)$ & 70.3 & 25.7 & 4.1 & 0.139 & 83.1 & 16.9 & 95.9 & 29.7 \\
\hline $\mathrm{UC}(\mathrm{n}=54)$ & 42.6 & 50.0 & 7.4 & 0.118 & 67.6 & 32.4 & 92.6 & 57.4 \\
\hline $\mathrm{UC}+\mathrm{PSC}(\mathrm{n}=74)$ & 48.6 & 45.9 & 5.4 & 0.267 & 71.6 & 28.4 & 94.6 & 51.4 \\
\hline $\operatorname{PSC}(n=40)$ & 65.0 & 32.5 & 2.5 & 0.684 & 81.3 & 18.7 & 97.5 & 35.0 \\
\hline
\end{tabular}

$\star$ Disease group $v$ controls.

CD, Crohn's disease; UC, ulcerative colitis; PSC, primary sclerosing cholangitis. 


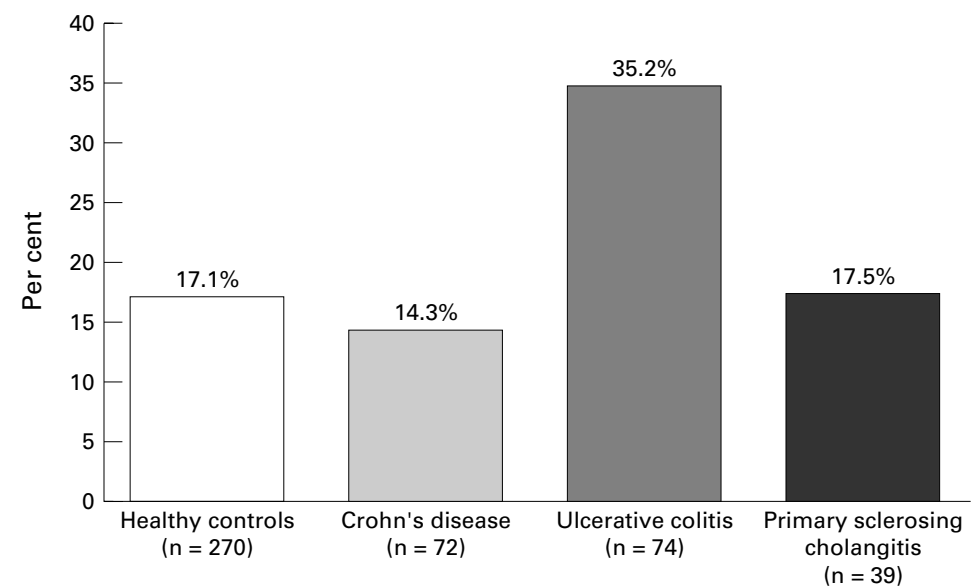

Figure 2 Percentage of persons carrying the combination of both the infrequent alleles of the Taq1 RFLP in ILIB and the Mwo1 RFLP in IL1RN.

$p=0.10$; see fig $4 A$ ). Furthermore, the reported relation between the Taq1 RFLP genotypes and IL-1 $\beta$ production (1/1: 1.5 (0.2), $1 / 2: 1.6$ (0.2), 2/2: $0.9(0.4) \mathrm{ng} / 10^{6}$ cells, $\mathrm{p}=0.50$; see fig $3 \mathrm{~A})$ or Mwo1 RFLP genotypes and IL-1 ra production (1/1: $6.3(0.5), 1 / 2: 7.0(0.6), 2 / 2$ : $7.3(0.6) \mathrm{ng} / 10^{6}$ cells, $\mathrm{p}=0.34$; see fig $\left.4 \mathrm{~B}\right)$ could not be confirmed.

Homozygotes for allele 2 of the BsoF1 RFLP tended to have higher IL-1 $\beta$ levels (fig $3 \mathrm{~B}$ ), and homozygotes for the MspA1 RFLP, and Mwo2 tended to have higher IL-1 ra levels (fig 4A and B), but this did not reach significance. Between carriers of allele 1 or allele 2 of the Alu1 RFLP the mean difference in IL-1 $\beta$ production was $0.19(0.27) \mathrm{ng} / 10^{6}$ cells (CI -0.35 to 0.73 $\mathrm{ng} / 10^{6}$ cells). Numbers for the BsoF1 RFLP and Taq1 RFLP were 0.07 (0.27) (CI -0.61 to $0.47) \mathrm{ng} / 10^{6}$ cells and $0.06(0.27)(\mathrm{CI}-0.48$ to $0.60) \mathrm{ng} / 10^{6}$ cells respectively. Between carriers of allele 1 or allele 2 the mean difference in IL-1 ra production was $0.71(0.79)$ (CI -0.87 to 2.3) $\mathrm{ng} / 10^{6}$ cells higher for the MspA1 RFLP and $0.72(0.76)(\mathrm{CI}-0.80$ to 2.2$) \mathrm{ng} / 10^{6}$ cells higher for the Mwo1 RFLP. Additionally we were interested whether the carriage of both infrequent alleles of the Taq1 and Mwo1 RFLPs, that are associated with UC, was reflected in the ratio between IL- $1 \beta$ and IL-1 ra production. Although carriers of both infrequent alleles of these RFLPs had a lower ratio of IL-1 ra and IL-1 $\beta$ production levels than non-carriers of these alleles, this difference did not reach significance $(\mathrm{p}=0.08)$ (fig 5$)$.

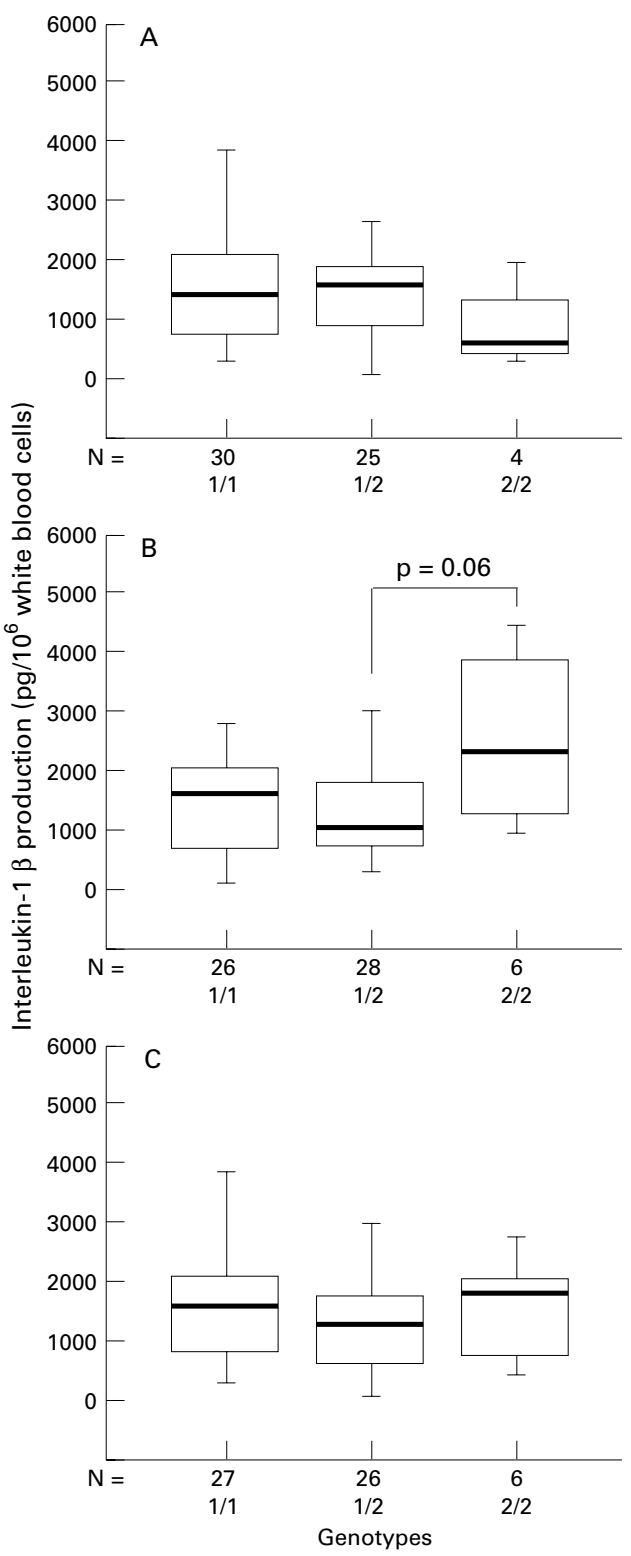

Figure 3 IL-1 $\beta$ production following ex vivo stimulation of whole blood with LPS in relation to genetic markers in IL1B. (A) Taq1; (B) BsoF1; (C) Alu1.

\section{Discussion}

Interleukin $1 \beta$ is a proinflammatory cytokine which is involved in the mucosal inflammatory response in IBD. Elevated mucosal levels of IL-1 $\beta$ have been reported in animal models of intestinal inflammation, and in patients with IBD. ${ }^{1013144041}$ Interleukin 1 receptor antagonist

Table 3 Mwo1 restriction fragment length polymorphism in the interleukin-1 receptor antagonist gene: genotype frequencies, allele frequencies and carriage rates in IBD

\begin{tabular}{|c|c|c|c|c|c|c|c|c|}
\hline \multirow[b]{2}{*}{ Mwo1 } & \multicolumn{4}{|c|}{ Genotype frequency } & \multicolumn{2}{|c|}{ Allele frequency } & \multicolumn{2}{|c|}{ Carriage rate } \\
\hline & $1 / 1$ & $1 / 2$ & $2 / 2$ & $p^{*}$ & 1 & 2 & 1 & 2 \\
\hline Healthy $(n=270)$ & 51,5 & 38,9 & 9,6 & & 70.9 & 29.1 & 90.4 & 48.5 \\
\hline $\mathrm{CD}(\mathrm{n}=63)$ & 41,3 & 47,6 & 11,1 & 0.351 & 65.1 & 34.9 & 88.9 & 58.7 \\
\hline CD+PSC $(n=72)$ & 45,8 & 44,4 & 9,7 & 0.719 & 68.1 & 31.9 & 90.3 & 54.2 \\
\hline $\mathrm{UC}(\mathrm{n}=55)$ & 49.1 & 47.3 & 3.6 & 0.382 & 72.7 & 27.3 & 96.4 & 50.9 \\
\hline $\mathrm{UC}+\mathrm{PSC}(\mathrm{n}=75)$ & 44.0 & 50.7 & 5.3 & 0.173 & 68.9 & 31,1 & 94.7 & 56.0 \\
\hline PSC $(n=40)$ & 50,0 & 45,0 & 5,0 & 0.649 & 72.5 & 27.5 & 95.0 & 50.0 \\
\hline
\end{tabular}

$\star$ Disease group $v$ controls.

CD, Crohn's disease; UC, ulcerative colitis; PSC, primary sclerosing cholangitis. 


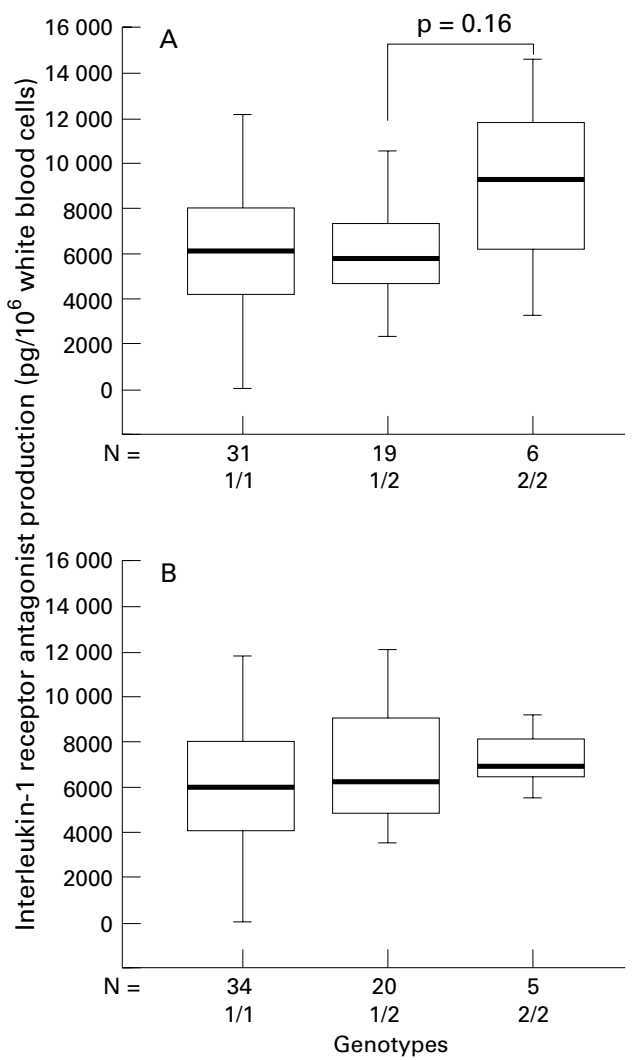

Figure 4 IL-1ra production following stimulation of whole blood with LPS in relation to genetic markers in IL1RN. (A) $M s p A I 1$; (B) Mwo1.

is a competitive inhibitor of IL-1 that binds to the IL-1 receptor but does not elicit postreceptor signalling. ${ }^{11}$ An imbalance between IL-1 $\beta$ and IL-1 ra may cause a proinflammatory state and has been suggested to underlie the mucosal inflammation found in IBD. ${ }^{15}$

We have used novel genetic markers to investigate whether IL-1B or IL-1RN determine genetic susceptibility to IBD, either alone or in conjunction. The MwoI RFLP, one of these markers, is in tight linkage disequilibrium with the other polymorphic markers in this region of IL1RN: Guash et al described an Msp1 RFLP at nt 8006 in exon 2, an Mwo1 RFLP at nt 8061 in intron 2, and an Ssp1 RFLP at nt 9586 in intron 3 and found a com-

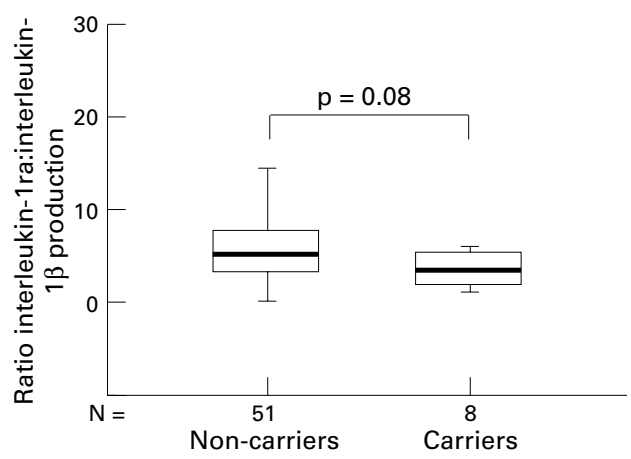

Figure 5 The ratio of IL-1ra and IL-1 $\beta$ production after LPS whole blood stimulation in healthy individuals carrying a combination of both infrequent alleles of the Taq1 and Mwo1 RFLPs (carriers) and in individuals that do not carry this combination (non-carriers). plete linkage disequilibrium between these three markers. ${ }^{32}$ The VNTR in intron 2 is situated between the Mwo1 RFLP and the Ssp1 RFLP of IL1RN. ${ }^{42}$ More recently, this finding was confirmed by another study. ${ }^{34}$ Therefore, allele 2 of the Mwo1 RFLP is on the same haplotype as allele 2 of the VNTR.

This study focuses on two issues: the relation of the markers in IL1B and IL1RN and IBD; and the relation between the markers and cytokine production.

\section{IL1B AND IL1RN RFLP IN IBD}

Patients with UC more frequently carried the combination of both the allele 2 of the Taq1 RFLP in IL-1B and the allele 2 of the Mwo 1 RFLP in IL-1RN. We could not confirm the reported association between UC and the polymorphism in intron 2 of the IL-1 ra gene alone. ${ }^{16}$ Nor did we find any additional association between the RFLPs and IBD, UC, or CD.

Our results are in sharp contrast to those of Bioque et $a l^{20}$ and Heresbach et al, ${ }^{21}$ who found a notable decrease in the number of individuals carrying the infrequent alleles of both the Taq1 RFLP in IL1B and the VNTR in IL1RN. Apparently this difference is caused by a high number of heterozygotes for the Taq1 RFLP in our population of patients with UC. Ethnic differences or patient selection on disease severity might contribute to this discrepancy.

Several studies have focused on the association between UC and allele 2 of the Il-1ra gene (which equates to our Mwo1 RFLP). Initially, two studies confirmed this association in a group of Hispanic patients with UC in Los Angeles ${ }^{18}$ and in a population from Pittsburgh in the United States. ${ }^{17}$ Another study only showed an increased frequency of allele 2 in patients with more severe UC but this result was not significant. ${ }^{43}$ The association with more severe disease in UC was also described by Roussomoustakaki et al in 107 patients with UC undergoing colectomy. ${ }^{44}$ In this study patients with more extensive colitis significantly more often carried allele 2 than patients with distal disease at the time of surgery. However, it should be noted that UC disease localisation seems to be a dynamic entity changing over time. ${ }^{45}$ Therefore associations with disease localisation should be interpreted with care. Furthermore, our data are in accordance with more recent studies from Europe that failed to show a significant increase in the allele frequency of allele 2 in UC..$^{2146}$

\section{IL1B AND IL1RN RFLP AND CYTOKINE} PRODUCTION

In a cohort of 60 healthy individuals we did not observe dependence of ex vivo cytokine production and IL1B or IL1RN genotypes. We were particularly interested in individuals carrying both infrequent alleles of the Taq1 RFLP and the Mwo1 RFLP, because we found an association between UC and carriage of both these alleles. Although these individuals had a lower ratio for IL-1 ra:IL-1 $\beta$ production levels this difference did not reach statistical significance. It should be noted that only eight 
individuals of the cohort of 60 were allele $2 / 2$ carriers and hence our study might lack power.

Others have studied cytokine production in relation to the Taq1 RFLP in IL1B and the VNTR in IL1RN. One study reported that the infrequent allele is associated with higher production of IL-1 ra by monocytes in vitro, ${ }^{23}$ whereas another suggested an association with lower levels of production in inflamed mucosa. ${ }^{24}$ Our study differs from these studies because we used whole blood stimulations, which are suggested to be a better reflection of the in vivo situation as all the blood components that might affect cytokine production are present and cell isolation artefacts are absent. The stimulus we applied was LPS whereas granulocyte/monocyte colony stimulating factor was used in monocyte cell cultures in the study that reported an association between a higher IL-1 ra production and the infrequent allele in IL1RN. ${ }^{23}$ LPS is a non-specific, but potent stimulus for IL-1 $\beta$ production and it also induces IL-1 ra production during human endotoxaemia. ${ }^{9}{ }^{47}$ As no key role for a specific inflammatory cell type has been defined in the pathogenesis of UC we assume that LPS is an appropriate stimulus for measuring IL- $1 \beta$ and Il-1 ra production.

Our data are in accordance with a recent study in which allele specific mRNA assessment was performed. In 33 keratinocyte cell lines, which were heterozygous for the tandem repeat in IL-1RN, both gene copies were transcribed equally after stimulation with phorbol myristate acetate. $^{34}$ However, these experiments and our study are ex vivo experiments and therefore we cannot conclude that the different alleles of IL1B and IL1RN do not reflect differences in vivo. In this context the study by Andus et al which showed lower mucosal IL-1 ra levels to be associated with allele 2 of IL1 RN is very interesting. ${ }^{24}$

In conclusion, ulcerative colitis is associated with carriage of both the infrequent alleles of the Taq1 RFLP and the Mwo1 RFLP in IL1B and IL1RN respectively. However, no evidence for a role for IL1B or IL1RN in the genetic control of IL-1 $\beta / \mathrm{IL}-1$ ra production rates or the pathogenesis of IBD has been found.

1 Duerr RH. Genetics of inflammatory bowel disease (review). Inflamm Bowel Dis 1996;2:48-60.

2 Satsangi J, Jewell P. Genetic markers in inflammatory bowel disease. Curr Opin Gastroenterol 1996;12:322-6.

3 Satsangi J, Welsh KI, Bunce M, et al. Contribution of genes of the major histocompatibility complex to susceptibility and disease phenotype in inflammatory bowel disease. and disease phenotype 1 .

4 Hugot JP, Laurent-Puig P, Gower-Rousseau C, et al. Hugot JP, Laurent-Puig P, Gower-Rousseau C, et al.
Linkage analyses of chromosome 6 loci, including HLA, in Linkage analyses of chromosome 6 loci, including HLA, in
familial aggregations of Crohn's disease. Am $\mathcal{F}$ Med Genet familial aggregation

5 Plevy SE, Targan SR, Yang H, et al. Tumor necrosis factor microsatellites define a Crohn's disease-associated haplotype on chromosome 6. Gastroenterology 1996;110:105360.

6 Satsangi J, Parkes M, Louis E, et al. Two stage genome-wide search in inflammatory bowel disease provides evidence for susceptibility loci on chromosomes 3, 7 and 12. Nat Genet 1996;14:199-202

7 Hugot JP, Laurent-Puig P, Gower-Rousseau C, et al. Mapping of a susceptibility locus for Crohn's disease on chromosome 16. Nature 1996;379:821-3.

8 Ohmen JD, Yang HY, Yamamoto KK, et al. Susceptibility locus for inflammatory bowel disease on chromosome 16 has a role in Crohn's disease, but not in ulcerative colitis. hum Mol Genet 1996;5:1679-83.

9 Dinarello CA, Wolff SM. The role of interleukin-1 in disease. N Engl F Med 1993;328:106-13.
10 Dinarello CA, Thompson RC. Blocking IL-1: interleukin-1 receptor antagonist in vivo and in vitro. Immunol Today receptor antagonist

11 Hannum CH, Wilcox CJ, Arend WP, et al. Interleukin-1 receptor antagonist activity of a human interleukin-1 inhibitor. Nature 1990;343:336-40.

12 Ligumsky M, Simon PL, Karmeli F, et al. Role of interleukin-1 in inflammatory bowel disease-enhanced production during active disease. Gut 1990;31:686-9.

13 Nakamura M, Saito H, Kasanuki J, et al. Cytokine production in patients with inflammatory bowel disease. Gut 1992;33:933-7.

14 Mahida YR, Wu K, Jewell DP. Enhanced production of interleukin- $1 \beta$ by mononuclear cells isolated from mucosa with active ulcerative colitis or Crohn's disease. Gut 1989; 30:835-8.

15 Casini-Raggi V, Kam L, Chong YL, et al. Mucosal imbalance of IL-1 and IL-1 receptor antagonist in inflammatory bowel disease. A novel mechanism of chronic intestinal inflammation. F Immunol 1995;154:2434-40.

16 Mansfield JC, Holden H, Tarlow JK, et al. Novel genetic association between ulcerative colitis and the antiinflammatory cytokine interleukin-1 receptor antagonist. Gastroenterology 1994;106:637-42.

17 Duerr RH, Tran T. Association between ulcerative colitis and a polymorphism in intron 2 of the interleukin-1 receptor antagonist gene [abstract]. Gastroenterology 1995;108: A812.

18 Tountas NA, Kam L, Digiovine FS, et al. Genetic association between allele 2 of IL-1 receptor antagonist (IL-1 ra) and ulcerative colitis in a Los Angeles based Hispanic population [abstract]. Gastroenterology 1995;108:

9 Louis E, Satsangi J, Roussomoustakaki M, et al. Cytokine gene polymorphisms in inflammatory bowel disease. Gut 996;39:705-10.

20 Bioque G, Crusius JBA, Koutroubakis I, et al. Allelic polymorphism in IL-1 $\beta$ and IL-1 receptor antagonist (IL-1 RA) genes in inflammatory bowel disease. Clin Exp Imтиnol 1995;102:379-83.

21 Heresbach D, Alizadeh M, Dabadie A, et al. Significance of interleukin-1 $\beta$ and interleukin-1 receptor antagonist in inflammatory bowel diseases. Am $\mathcal{F}$ Gastroenterol 1997;92: 1164-9.

22 Pociot F, Molvig J, Wogensen L, et al. A TaqI polymorphism in the human interleukin-1 $\beta$ (IL-1 $\beta$ ) gene correlates with IL-1 $\beta$ secretion in vitro. Eur F Clin Invest 1992;22:396-402.

23 Danis VA, Millington M, Hyland VJ, et al. Cytokine production by normal human monocytes: inter-subject variation and relationship to an IL-1 receptor antagonist (IL-1Ra) gene polymorphism. Clin Exp Immunol 1995;99:303-10.

24 Andus T, Vogl D, Ashenbrenner E, et al. IL-1 ra genotype 2 is associated with reduced IL-1 ra in colonic mucosa [abstract]. Gastroenterology 1996;108:A3070.

25 Webb AC, Collins KL, Auron PE, et al. Interleukin-1 gene (IL-1) assigned to long arm of chromosome 2. Lymphokine Res 1986;5:77-85.

26 Furutani Y, Notake M, Fukui T, et al. Complete nucleotide sequence of the gene for human interleukin 1 alpha. Nucleic Acids Res 1986;14:3167-79.

27 Modi WS, Masuda A, Yamada M, et al. Chromosomal localization of the human interleukin-1 $\alpha$ (IL1 $\alpha$ ) gene. Genomics 1988;2:310-14.

28 Lafage $\mathrm{M}$, Maroc N, Dubreuil $\mathrm{P}$, et al. The human interleukin- $1 \alpha$ gene is located on the long arm of chromo-
some 2 at band q13. Blood 1989;73:104-7.

29 Steinkasserer A, Spurr NK, Cox S, et al. The human IL-1 receptor antagonist gene (IL1RN) maps to chromosome
$2 \mathrm{q} 14-21$, in the region of the IL-1 $\alpha$ and IL-1 $1 \beta$ loci. Genomics 1992;13:654-7.

30 Patterson D, Jones C, Hart I, et al. The human interleukin-1 receptor antagonist is located in the chromosome $2 \mathrm{q} 14$ region. Genomics 1993;15:173-6.

31 Lennard A, Gorman P, Carrier M, et al. Cloning and chromosome mapping of the interleukin-1 receptor antagonist gene. Cytokine 1993;4:83-9.

32 Guash JF, Bertina RM, Reitsma P. Five novel intragenic dimorphisms in the human interleukin-1 genes combine to high informativity. Cytokine 1996;8:598-602.

33 Sambrook J, Fritsch EF, Maniatis T. In: Molecular cloning. 2nd edn. New York: Cold Spring Harbor Laboratory, 1989:16-19.

34 Clay JF, Tarlow JK, Cork MJ, et al. Novel interleukin-1 receptor antagonist exon polymorphisms and their use in allele specific mRNA assessment. Hum Genet 1996;97:723-

35 Entzian P, Linneman K, Schlaak M, Zabel P. Obstructive sleep apnea syndrome and circadian rhythms of hormones and cytokines. Am F Respir Crit Care Med 1996;153:10806.

36 Nerad JL, Griffiths JK, Van der Meer JWM, et al. Interleukin-1 $\beta$ (IL-1 $\beta$ ), interleukin-1 receptor antagonist, and TNF $\alpha$ production in whole blood. F Leukoc Biol 1992; 52:687-92.

37 De Groote D, Zangerle PF, Gevaert Y, et al. Direct stimulation of cytokines (IL- $1 \beta$, TNF- $\alpha$, IL- 6, IL-2, IFN- $\gamma$ and GM-CSF) in whole blood. I. Comparison with isolated PBMC stimulation. Cytokine 1992;4:239-48.

38 Sham PC, Curtis D. Monte Carlo tests for associations between disease and alleles at highly polymorphic loci. Ann Hum Genet 1995;59:97-105.

39 Altman DG. Comparing risks. In: Practical statistics for medical research. 1st edn. London: Chapman \& Hall, 1993: 266-8. 
40 Rachmilewitz D, Simon PL, Schwartz LW, et al. Inflammatory mediators of experimental colitis in rats. Gastroenterology 198

41 Cominelli F, Nast CC, Clark BD, et al. Interleukin-1 (IL1) gene expression, synthesis, and effect of specific IL-1 receptor blockade in rabbit immune complex colitis. $f$ Clin Invest 1990;86:972-80.

42 Tarlow JK, Blakemore AIF, Lennard A, et al. Polymorphism in human IL-1 receptor antagonist gene intron 2 is caused by variable number of an $86-$ bp tandem repeat. Hum Genet 1993;91:403-1

43 Andus T, Caesar I, Vogl D, et al. Association of HLA-DR15, pANCA and IL-1 receptor antagonist allele 2 with ulcerative colitis [abstract]. 1995;108:A770.
44 Roussomoustakaki M, Satsangi J, Welsh K, et al. Genetic marker may predict disease behavior in patients with ulcerative colitis. Gastroenterology 1997;112:1845-53.

45 Langholz E, Nielsen OH, Munkholm P, et al. Course and prognostic factors influencing changes in anatomical extent of ulcerative colitis [abstract]. Gastroenterology 1995;108: A857.

46 Hacker UT, Gomolka M, Keller E, et al. Lack of association between an interleukin-1 receptor gene polymorphism and ulcerative colitis. Gut 1997;40:623-7.

47 Granowitz EV, Santos AA, Poutsiaka DD, et al. Production of interleukin-1-receptor antagonist during experimental endotoxaemia. Lancet 1991;338:1423-4. 